\title{
Differences in Dental Arch Dimensions in a Sample of Kurdish Population among Different Occlusal Categories (Ex Vivo Study)
}

\author{
Rawand J. Othman ${ }^{1 *}$, Hiwa S. Khidir ${ }^{2}$ \\ ${ }^{1}$ Department of Orthodontics, Khanzad Teaching Center, Ministry of Health, Erbil, Kurdistan Region, Iraq, ${ }^{2}$ Department of Dental Assistant, \\ Erbil Technical Medical Institute, Erbil Polytechnic University, Erbil, Kurdistan Region, Iraq
}

\author{
*Corresponding author: \\ Rawand J. Othman, \\ Department of Orthodontics, \\ Khanzad Teaching Center, \\ Ministry of Health, Erbil, \\ Kurdistan Region, Iraq. \\ E-mail: rawandden@gmail.com
}

Received: 08 October 2019

Accepted: 19 January 2020

Published: 30 June 2020

DOI

10.25156/ptj.v10n1y2020.pp51-55

\section{A B S T R A C T}

It is essential to know dental arch dimensions to provide accurate diagnosis and treatment planning to ensure the satisfactory outcome of orthodontic treatment. The aim of the present study was to measure and compare dental arch dimensions of a Kurdish sample in Erbil city with normal and different classes of malocclusion. Arch width and length were measured by an electronic digital caliper on a total of 150 orthodontic models of school students aged 16-20 years of different occlusal relationships (Class I normal occlusion, Class I, Class II division I, Class II Division II, and Class III malocclusions). The results showed that (1) girls have smaller arch parameters than boys; (2) Class II division II malocclusion showed a significantly smaller upper inter canine width, arch length, incisor molar distance, and incisor canine distance when compared to all other groups; (3) the upper inter premolar and inter molar width were significantly narrower in Class II division I malocclusion than of normal occlusions and Class III malocclusion and also narrower in Class I malocclusion than in normal occlusions for both arches; (4) the arch length was significantly longer in Class II division I when compared to Class II division II, Class I malocclusions $(P<0.01)$, Class III malocclusion and Class I normal occlusion $(P<0.05)$, and (5) no statistically significant differences were found in all the arch dimensions for Class III malocclusion when compared with the normal occlusion. In conclusion, girls had smaller arch dimension than boys and Class II Division II malocclusion showed smaller arch in all dimensions while Class II division I malocclusion revealed narrower arch width and longer arch length.

Keywords: Arch length; Arch width; Dental arch dimension; Malocclusion; Orthodontics

\section{INTRODUCTION}

It is an important to have data concerning relevant human group for purposes of clinical diagnosis and planning of treatment. The ethnic differences in arch dimensions should be considered during treatment, especially in prosthodontics and orthodontics where arch shape can be modified appreciably (Burris and Harris, 2000).

Several studies were carried out on arch width and transverse craniofacial development to evaluate changes due to growth, treatment, and relapse (Knott, 1972). Some studies investigated the transverse morphology and growth of Class II division 1 and Class II division II compared to Class I (Staley et al., 1985; Lux et al., 2003). Very few studies, however, included the four types of anteroposterior occlusion groups in their comparisons (Kook et al., 2004).

Researchers around the world had studied tooth size and dental arch dimensions of different populations. Scant researches have been done on dental casts of the
Kurdish population to determine the clinical significance of maxillary and mandibular tooth size measurements and dental arch dimension in orthodontic diagnosis and treatment planning (Mahmood, 2012).

It is well documented in the literature that using preformed archwires for orthodontic patients, regardless of their arch form, will lead to post-treatment instabilities in the form of relapse (Engel, 1979). Accordingly, there have to be shifts from using preformed archwires routinely for all patients to selecting specific archwires for individual patients, depending on his or her arch form and malocclusion adaptability. Several researchers had been trying to classify the dental arch forms. It is accepted that the dental arch is shaped and confined by the supporting bone configurations and it is affected by the eruption of teeth and the surrounding muscular forces (Moorrees, 1959), especially in modern orthodontic techniques, in which preformed super elastic archwires are frequently used. Clinically, instead of one preformed archwire, it is more reasonable to have several types of preformed archwires available and 
to identify the patient's pretreatment arch form according to race and malocclusion (Kook et al., 2004).

Dental casts are still considered a vital diagnostic tool in orthodontic practice. They facilitate the analysis of tooth size and shape; alignment and rotations of the teeth, arch width, length, form and symmetry, and the occlusal relationship (Hashim and Al-Ghamdi, 2005).

Hence, the aim of the present study was to compare the arch dimension between the different categories of occlusion and genders in Class I normal occlusion groups.

\section{MATERIALS AND METHODS}

The study sample was obtained from students of secondary schools selected randomly after dividing the city into four geographical areas (North, South, East, and West), a total of 4258 (2213 boys, and 2045 girls) were examined from 15 schools, eight schools for males, and seven schools of females, within period of 1 month.

The ethical approvals for conducting the study and sample selection were obtained from the Ethical Committee of research in College of Dentistry/Hawler Medical University. Permission has been taken from the school principal before starting the examination. Informed consent to participate and maintain confidentiality was observed. Before data collection researcher explained, the objectives of this study were to students and requested consent for participation in the study. The following inclusion criteria were used:

1. Kurdish student from Kurdish parents living in Erbil city

2. Complete permanent dentition excluding the second and third molars

3. All teeth are fully erupted to the occlusal plane.

Out of 4258 examined students 150 were selected according to special criteria, the selected samples were furthered more divided into five subgroups of 30 (15 boys and 15 girls) based on angle classification groups.

The subjects in this study were classified to the different groups of occlusion based on the categories of occlusion coincident with the skeletal categories. Occlusal relationships were classified according to Angle's classification (1899) of molar position in centric occlusion, whereas the skeletal diagnosis was made on the basis of ANB angle values on lateral cephalometric using Al-Sahaf standards of Iraqi adults (Al-Sahaf, 1991). The following criteria were adopted for the normal occlusion cases:

- Normal ANB angle $\left(2-4^{\circ}\right)$

- Class I molar relationship which was selected according to "Angle classification"
- There is no tipping or rotation of any tooth and no spacing or crowding

- Normal overjet and overbite (3-4 mm) (Luffingham and Campbell, 1974)

- No midline deviations in the maxillary or mandibular dental arches.

In our sample, the criteria for the Class I malocclusion were that the molar relationship should follow the criteria of Angle's' Classification for Class I occlusion and ANB angle of $2-4^{\circ}$, but with crowding more than $3 \mathrm{~mm}$.

The sample criteria for Class II malocclusion were that the molars relationship should follow the criteria of Angle's classification for Class II and having ANB angle greater than $4^{\circ}$ and depending on maxillary central incisor position according to the British Standards Institute classification (1983) classified into Class II division 1 and Class II division 2, while in the sample criteria for Class III malocclusion, the molar relationship should follow the criteria of Angle's' classification for Class III malocclusion and $\mathrm{ANB}$ angle $<2^{\circ}$.

Complete dental impressions were obtained for the upper and lower arches, using alginate (Zhermack, Italy) with perforated plastic tray that had been disinfected. The impressions were poured with yellow stone (Zhermack, Italy).

The following representative measurements of arch width were obtained: Inter-canine distance (ICD), inter-premolar distance, and intermolar distance while the arch length measurements were the canine vertical distance (CVD) and the molar vertical distance (MVD).

Measurements for dental arch length and width were taken from the study casts using an electronic digital caliper (Hogetex, Germany) accurate up to $0.01 \mathrm{~mm}$ with some reference points were marked on the models by means of a $6 \mathrm{H}$ sharp pencil, as shown in Figure 1.

An intra-examiner calibration was carried out twice by the researcher, with time lapse of 2 weeks between the two measurements to overcome the memory bias; these were the first reading and the second reading. For inter-examiner calibration, the same measurements were carried out by a well-trained dentist for the same models, this was the third reading and it is compared to the first reading.

$t$-value of intra-examiner and inter-examiner readings revealed non-significant differences between the mean values of all measurements. 


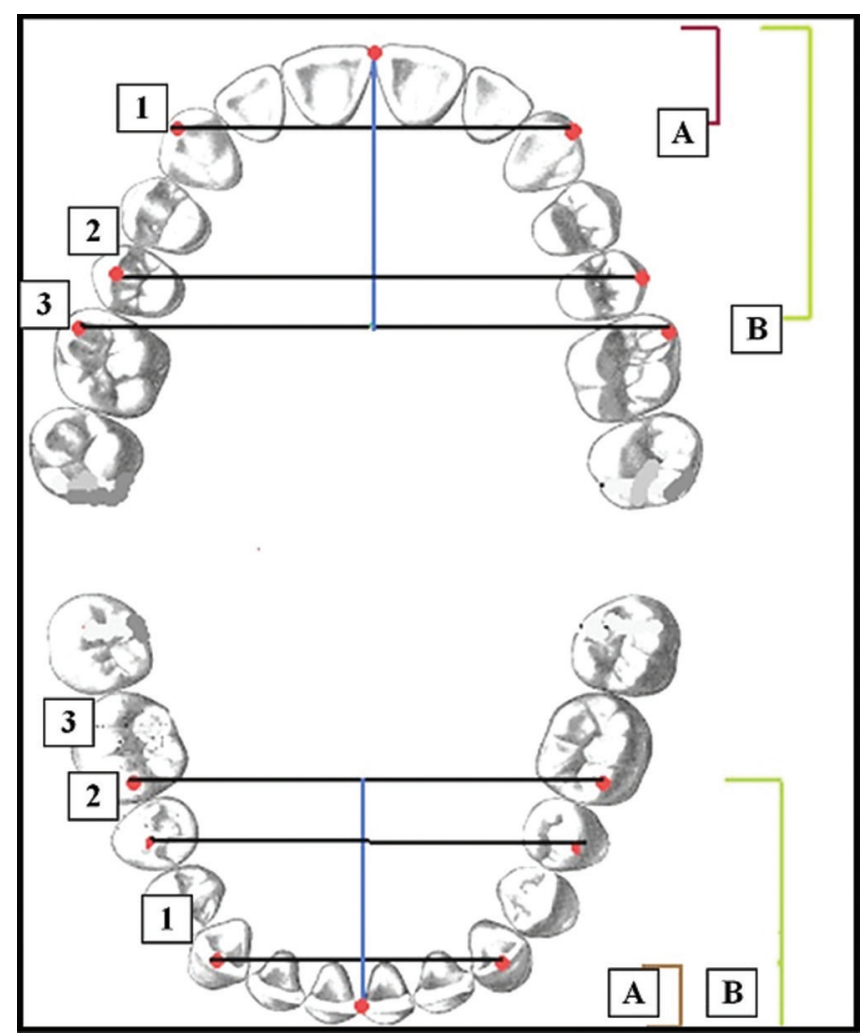

Figure 1: Linear arch dimensions measurements

Arch width: 1 (intercanine), 2 (inter-premolar), 3 (inter-molar) Arch length: A (canine-vertical), B (molar-vertical), (Researcher)

\section{RESULTS AND DISCUSSION}

The finding of the present study for Class I normal occlusion in Tables 1 and 2 showed a significant difference in the maxillary and mandibular inter-premolar, intermolar distance, and CVD with greater mean value in boys. According to Younes (1984), this may be attributed to the smaller and smoother bony ridge and alveolar process of girls and the average weakness of musculature in girls that play an important role in facial breadth measurements, width and height of the dental arch.

Cassidy et al. (1998) found a high degree of sexual dimorphism among siblings, with boys having arch widths, depths, and segment measurements 3-5\% higher than their female counterparts.

Tables 3 and 4 show the results of ANOVA and LSD post hoc test which pinpoint the differences of means between each two groups of the skeletal classes. The lower ICD in the current study was smaller in Class II Division II when compared to Class II Division I and our result agreed with other studies that compared the two types of Class II malocclusion (Walkow and Peck, 2002; Uysal et al., 2005).

In the current study, the mandibular widths tended to be slightly smaller in subjects with Class I malocclusion
Table 1: The general distribution of the sample

\begin{tabular}{lccc}
\hline Groups & Male & Female & Total No. \\
\hline Class I normal (control) & 15 & 15 & 30 \\
Class I malocclusion & 15 & 15 & 30 \\
Class II division I malocclusion & 15 & 15 & 30 \\
Class II division II malocclusion & 15 & 15 & 30 \\
Class III malocclusion & 15 & 15 & 30 \\
Total No. & 75 & 75 & 150 \\
\hline
\end{tabular}

Table 2: Comparison between boys and girls for arch dimensions in the upper and lower dental arches in Class I normal occlusion group

\begin{tabular}{|c|c|c|c|c|c|c|}
\hline \multirow[t]{2}{*}{ Variable } & \multicolumn{2}{|c|}{ Male } & \multicolumn{2}{|c|}{ Female } & \multirow[t]{2}{*}{$t$-test } & \multirow[t]{2}{*}{$P$-value } \\
\hline & Mean & S.D & Mean & S.D. & & \\
\hline \multicolumn{7}{|l|}{ Upper arch } \\
\hline $\begin{array}{l}\text { Inter-canine } \\
\text { distance }\end{array}$ & 34.82 & 1.53 & 34.16 & 1.58 & 1.17 & 0.25 \\
\hline $\begin{array}{l}\text { Inter-premolar } \\
\text { distance }\end{array}$ & 47.79 & 2.59 & 46.00 & 1.70 & 2.23 & $0.034^{*}$ \\
\hline Intermolar distance & 53.74 & 2.79 & 51.28 & 2.12 & 2.72 & $0.011^{*}$ \\
\hline $\begin{array}{l}\text { Canine vertical } \\
\text { distance }\end{array}$ & 9.29 & 1.06 & 8.22 & 1.22 & 2.56 & $0.016^{\star}$ \\
\hline $\begin{array}{l}\text { Molar vertical } \\
\text { distance }\end{array}$ & 28.49 & 2.15 & 27.33 & 2.75 & 1.29 & 0.21 \\
\hline \multicolumn{7}{|l|}{ Lower arch } \\
\hline $\begin{array}{l}\text { Inter-canine } \\
\text { distance }\end{array}$ & 26.42 & 1.91 & 25.75 & 1.60 & 1.03 & 0.31 \\
\hline $\begin{array}{l}\text { Inter-premolar } \\
\text { distance }\end{array}$ & 40.30 & 2.60 & 38.22 & 1.78 & 2.56 & $0.016^{*}$ \\
\hline Intermolar distance & 46.28 & 3.18 & 43.67 & 1.40 & 2.63 & 0.023 * \\
\hline $\begin{array}{l}\text { Canine vertical } \\
\text { distance }\end{array}$ & 5.95 & 0.76 & 5.23 & 0.89 & 2.39 & $0.024^{*}$ \\
\hline $\begin{array}{l}\text { Molar vertical } \\
\text { distance }\end{array}$ & 24.34 & 1.71 & 23.55 & 2.06 & 1.14 & 0.26 \\
\hline
\end{tabular}

${ }^{*}$ Significant at $P<0.05$. ${ }^{*}$ Highly significant at $P<0.01$. N.B: All dimensions are in $\mathrm{mm}$

than those with normal occlusion, with differences for interpremolar $(P=0.048)$ and intermolar $(P=0.049)$ dimensions attaining significant levels, similar results were reported by Alvaran et al. (2009).

The current study showed that the maxillary interpremolar widths in Class II division I and division II were significantly smaller than that in the other classes. Similar results were reported for Class II division 1 when compared with Class I normal occlusion (Staley et al., 1985; Sayin and Turkkahraman, 2004).

The differences between the maxillary intermolar widths were significantly larger in normal occlusion when compared with Class II division I and II subjects. In the mandible, the same tendency is fond, but group differences were not statistically significant. The same results were reported for Class II division 1 when compared with Class I normal occlusion in other studies (Staley et al., 1985; Lux et al., 2003). 
Table 3: ANOVA table for the arch widths and arch lengths of all skeletal classes

\begin{tabular}{|c|c|c|c|c|c|c|c|c|c|c|c|c|}
\hline \multirow[t]{2}{*}{ Variable } & \multicolumn{2}{|c|}{ Class I Normal } & \multicolumn{2}{|c|}{ Class I Mal. } & \multicolumn{2}{|c|}{ Class II Div. I } & \multicolumn{2}{|c|}{ Class II Div. II } & \multicolumn{2}{|c|}{ Class III } & \multirow[t]{2}{*}{ F-test } & \multirow[t]{2}{*}{$P$-value } \\
\hline & Mean & S.D. & Mean & S.D. & Mean & S.D. & Mean & S.D. & Mean & S.D. & & \\
\hline \multicolumn{13}{|l|}{ Upper arch } \\
\hline Inter-canine distance & 34.49 & 1.57 & 34.14 & 2.56 & 33.74 & 2.30 & 32.62 & 2.55 & 34.13 & 1.83 & 3.28 & $0.013^{*}$ \\
\hline Inter-premolar distance & 46.89 & 2.34 & 45.33 & 2.65 & 43.74 & 2.58 & 44.08 & 3.16 & 46.95 & 3.15 & 8.76 & $0.000^{* *}$ \\
\hline Intermolar distance & 52.51 & 2.73 & 50.34 & 3.05 & 49.32 & 2.82 & 50.40 & 2.40 & 52.57 & 3.38 & 7.48 & $0.000^{* *}$ \\
\hline Canine vertical distance & 8.75 & 1.25 & 8.61 & 2.02 & 9.94 & 1.86 & 4.96 & 1.54 & 8.07 & 1.53 & 37.75 & $0.000^{* *}$ \\
\hline Molar vertical distance & 27.91 & 2.50 & 29.41 & 2.57 & 30.72 & 2.99 & 24.19 & 2.02 & 26.90 & 2.14 & 30.75 & $0.000^{* *}$ \\
\hline \multicolumn{13}{|l|}{ Lower arch } \\
\hline Inter-canine distance & 26.09 & 1.76 & 25.52 & 1.93 & 26.78 & 2.11 & 25.69 & 1.54 & 26.64 & 2.07 & 2.62 & $0.037^{*}$ \\
\hline Inter-premolar distance & 39.26 & 2.43 & 37.93 & 2.76 & 39.08 & 2.48 & 39.04 & 2.22 & 38.99 & 3.10 & 1.24 & 0.298 \\
\hline Intermolar distance & 44.97 & 2.76 & 43.61 & 2.61 & 44.65 & 2.22 & 44.77 & 2.06 & 44.91 & 3.27 & 1.35 & 0.253 \\
\hline Canine vertical distance & 5.59 & 0.89 & 5.33 & 1.66 & 6.68 & 1.45 & 5.24 & 1.01 & 5.06 & 1.30 & 7.47 & $0.000^{* *}$ \\
\hline Molar vertical distance & 23.95 & 1.90 & 23.90 & 2.84 & 25.35 & 1.94 & 22.85 & 2.24 & 23.13 & 1.97 & 5.85 & $0.000^{* *}$ \\
\hline
\end{tabular}

*Significant at $P<0.05$. **Highly significant at $P<0.01$. N.B: All dimensions are in $\mathrm{mm}$

Table 4: LSD post hoc test of arch widths and arch lengths for all skeletal classes

\begin{tabular}{|c|c|c|c|c|c|c|c|c|c|c|}
\hline Variable & $\begin{array}{l}\text { Class I } \\
\text { Normal and } \\
\text { Class I Mal. }\end{array}$ & $\begin{array}{l}\text { Class I } \\
\text { Normal and } \\
\text { Class II } \\
\text { Div.I }\end{array}$ & $\begin{array}{c}\text { Class I } \\
\text { Normal } \\
\text { and Class II } \\
\text { Div.II } \\
\end{array}$ & $\begin{array}{l}\text { Class I } \\
\text { Normal } \\
\text { and } \\
\text { Class III } \\
\end{array}$ & $\begin{array}{l}\text { Class I } \\
\text { Mal. and } \\
\text { Class II } \\
\text { Div.I } \\
\end{array}$ & $\begin{array}{l}\text { Class I } \\
\text { Mal. and } \\
\text { Class II } \\
\text { Div.II } \\
\end{array}$ & $\begin{array}{l}\text { Class I } \\
\text { Mal and } \\
\text { Class III }\end{array}$ & $\begin{array}{l}\text { Class II } \\
\text { Div.I and } \\
\text { Class II } \\
\text { Div.II } \\
\end{array}$ & $\begin{array}{l}\text { Class II } \\
\text { Div. I and } \\
\text { Class III }\end{array}$ & $\begin{array}{l}\text { Class II } \\
\text { Div. II } \\
\text { and } \\
\text { Class III }\end{array}$ \\
\hline & $P$-value & $P$-value & $P$-value & $P$-value & $P$-value & $P$-value & $P$-value & $P$-value & $P$-value & $P$-value \\
\hline \multicolumn{11}{|l|}{ Upper arch } \\
\hline $\begin{array}{l}\text { Inter-canine } \\
\text { distance }\end{array}$ & 0.53 & 0.18 & $0.001^{*}$ & 0.52 & 0.48 & $0.01^{*}$ & 0.99 & $0.05^{*}$ & 0.49 & $0.008^{* *}$ \\
\hline $\begin{array}{l}\text { Inter-premolar } \\
\text { distance }\end{array}$ & $0.032^{*}$ & $0.000^{* *}$ & $0.000^{* *}$ & 0.94 & $0.029^{*}$ & 0.08 & $0.027^{\star}$ & 0.64 & $0.000^{* *}$ & $0.000^{* *}$ \\
\hline $\begin{array}{l}\text { Intermolar } \\
\text { Distance }\end{array}$ & $0.004^{\star *}$ & $0.000^{* *}$ & $0.005^{\star *}$ & 0.93 & 0.18 & 0.93 & $0.003^{* *}$ & 1.15 & $0.000^{* *}$ & $0.004^{* *}$ \\
\hline CVD & 0.74 & $0.006^{\star *}$ & $0.000^{* *}$ & 0.11 & $0.002^{* *}$ & $0.000^{* *}$ & 0.21 & $0.000^{* *}$ & $0.000^{\star *}$ & $0.000^{* *}$ \\
\hline MVD & $0.02^{*}$ & $0.000^{\star \star}$ & $0.000^{\star *}$ & 0.11 & $0.009^{*}$ & $0.000^{\star *}$ & $0.000^{\star *}$ & $0.000^{\star *}$ & $0.000^{* *}$ & $0.000^{* *}$ \\
\hline \multicolumn{11}{|l|}{ Lower arch } \\
\hline $\begin{array}{l}\text { Inter-canine } \\
\text { distance }\end{array}$ & 0.25 & 0.16 & 0.42 & 0.26 & $0.011^{*}$ & 0.73 & $0.023^{*}$ & $0.03^{*}$ & 0.77 & 0.054 \\
\hline $\begin{array}{l}\text { Inter-premolar } \\
\text { distance }\end{array}$ & $0.048^{*}$ & 0.79 & 0.74 & 0.69 & 0.09 & 0.1 & 0.12 & 0.95 & 0.89 & 0.94 \\
\hline $\begin{array}{l}\text { Intermolar } \\
\text { Distance }\end{array}$ & $0.049^{*}$ & 0.63 & 0.77 & 0.92 & 0.13 & 0.09 & 0.06 & 0.85 & 0.7 & 0.84 \\
\hline CVD & 0.44 & $0.001^{* *}$ & 0.29 & 0.11 & $0.000^{* *}$ & 0.78 & 0.42 & $0.000^{* *}$ & $0.000^{* *}$ & 0.59 \\
\hline MVD & 0.94 & $0.01^{*}$ & 0.06 & 0.15 & $0.01^{*}$ & 0.07 & 0.18 & $0.000^{* *}$ & $0.000^{* *}$ & 0.62 \\
\hline
\end{tabular}

*Significant at $P<0.05$. ${ }^{* *}$ Highly significant at $P<0.01$. N.B: All dimensions are in $\mathrm{mm}$

In 1984, Bjork et al. stated that a narrow maxilla in Class II is likely to be a key factor in the development of the malocclusion. Narrow maxillary arch widths among Class II subjects have been attributed to airway obstruction and mouth breathing (Seto et al., 2001), habits (Warren et al., 2001), and abnormal muscle function (Brader, 1972). Adolescents with Class II malocclusion have narrow maxillary arch widths (Lux et al., 2003; Alvaran et al., 2009).

Both the maxillary CVD and MVD in Class II division I malocclusions were longer than that of other classes, this finding agreed with that reported by Buschang et al. (1994) especially for girls group.
While in the Class II division II malocclusions it was shorter than it is in all the other classes, which is an expected result, considering the proclination of the maxillary central incisors in Class II division 1 and the retroclination in Class II division II malocclusions.

Furthermore, in this study, similar findings are seen in the lower MVD and CVD in Class II division I malocclusions as they were longer than the other classes, one possible reason for this may be that Class II division I malocclusions cases typically have significantly more overjet so that the lower incisors teeth may have more room to Procline resulting in increased the lower arch length. 
The upper molar-vertical distance in the current study is increased in Class I malocclusion when compared with the normal group. This result is in accordance with the finding of Howe et al. (1983), but in disagreement with the studies carried out by Radnzic, 1988; and Al-Timimy, 2000 , and these may be attributed to the differences in age groups, ethnic groups, and landmarks and procedures used in their study.

\section{CONCLUSIONS}

Based on the findings, it can be concluded that there were a significant reductions in the inter molar and inter premolar widths for Class I malocclusion when compared with the normal group in both arches and Class II division I malocclusion showed a significantly narrower upper inter premolar and inter-molar width when compared to normal occlusions and Class III malocclusion and longer arch length when compared to all other groups in both arches while a Class II division II malocclusion showed a significantly smaller upper inter canine width, arch length, incisor molar, and incisor canine when compared to all other groups.

Further studies are recommended to determine the arch forms and facial forms in the normal and different types of malocclusion in a Kurdish sample.

\section{REFERENCES}

Al-Sahaf, N. H. 1991. Cross-Sectional Study of Cephalometric Standards and Associated Growth Changes, A Master Thesis, Department of Pedodontics, Orthodontics, and Preventive Dentistry. University of Baghdad, Baghdad.

Al-Timimy, I. A. 2000. Anterior Dental Crowding and its Relationship to Mesiodistal Crown Diameter of the Teeth and Arch Dimension in three Classes of Molar Relation, A Master Thesis, College of Dentistry. Baghdad University, Iraq.

Alvaran, N., S. I. Roldan and P. H. Buschang. 2009. Maxillary and mandibular arch widths of Colombians. Am. J. Orthod. Dentofacial Orthop. 135(5): 649-656.

Angle, E. H. 1899. Classification of malocclusion. Dent. Cosm. 41: 284-264.

Bjork, A., T. Brown and V. Skieller. 1984. Comparison of craniofacial growth in Australian Aboriginal and Danes, illustrated by longitudinal cephalometric analysis. Eur. J. Orthod. 6(1): 1-14.

Brader, A. C. 1972. Dental arch form related with intraoral forces: $\mathrm{PR}=$ C. Am. J. Orthod. 61(6): 541-561.

British Standards Institution. 1983. British Standard Glossary of Dental Terms. British Standards Institution, United Kingdom.

Burris, B. G. and E. F. Harris. 2000. Maxillary arch size and shape in American blacks and whites. Angle Orthod. 70(4): 297-302.
Buschang, P. H., J. Stroud and R. G. Alexander. 1994. Differences in dental arch morphology among adult females with untreated Class I and Class II malocclusion. Eur. J. Orthod. 16(1): 47-52.

Cassidy, K. M., E. F. Harris, E. A. Tolley and R. G. Keim. 1998. Genetic influence on dental arch form in orthodontic patients. Angle Orthod. 68(5): 445-454.

Engel, G. A. 1979. Preformed arch wires: Reliability of fit. Am. J. Orthod. Dentofacial Orthop. 76(5): 497-504.

Hashim, H. A. and S. Al-Ghamdi. 2005. Tooth width and arch dimensions in normal and malocclusion samples: An odontometric study. J. Contemp. Dent. Pract. 6(2): 36-51.

Howe, R. P., J. A. Jr. McNamara and K. A. O'Connor. 1983. An examination of dental crowding and its relationship to tooth size and arch dimension. Am. J. Orthod. 83(5): 363-373.

Knott, V. B. 1972. Longitudinal study of dental arch widths at four stages of dentition. Angle Orthod. 42(4): 387-394.

Kook, Y. A., K. Nojima, H. B. Moon, R. P. McLaughlin and P. M. Sinclair. 2004. Comparison of arch forms between Korean and North American white populations. Am. J. Orthod. Dentofacial Orthop. 126(6): 680-686.

Luffingham, J. K. and H. M. Campbell. 1974. The need for orthodontic treatment. A pilot survey of 14 year old school children in Paisley, Scotland. Trans. Eur. Orthod. Soc.: 259-267.

Lux, C. J., C. Conradt, D. Burden and G. Komposch. 2003. Dental arch widths and mandibular-maxillary base widths in Class II malocclusions between early mixed and permanent dentitions. Angle Orthod. 73(6): 674-685.

Mahmood, A. D. 2012. A Comparative study of tooth size and dental arch dimensions between Iraqi Arabs and Kurds with Class I normal occlusion. Al-Rafidain Dent. J. 12(1): 71-79.

Moorrees, C. F. 1959. The Dentition of the Growing Child: A Longitudinal Study of Dental Development between 3 and 18 Years of Age. Harvard University Press, Cambridge.

Radnzic, D. 1988. Dental crowding and its relationship to mesiodistal crown diameters and arch dimensions. Am. J. Orthod. Dentofacial Orthop. 94(1): 50-56.

Sayin, M. O. and H. Turkkahraman. 2004. Comparison of dental arch and alveolar widths of patients with Class II, Division 1 malocclusion and subjects with Class I ideal occlusion. Angle Orthod. 74(3): 356-360.

Seto, B. H., H. Gotsopoulos, M. R. Sims and P. A. Cistulli. 2001. Maxillary morphology in obstructive sleep apnoea syndrome. Eur. J. Orthod. 23(6): 703-714.

Staley, R. N., W. R. Stuntz and L. C. Peterson. 1985. A comparison of arch widths in adults with normal occlusion and adults with Class II, Division 1 malocclusion. Am. J. Orthod. 88(2): 163-169.

Uysal, T., B. Memili, S. Usumez and Z. Sari. 2005. Dental and alveolar arch widths in normal occlusion, Class II Division 1 and Class II Division 2. Angle Orthod. 75(6): 941-947.

Walkow, T. M. and S. Peck. 2002. Dental arch width in Class II Division 2 deep-bite malocclusion. Am. J. Orthod. Dentofacial Orthop. 122(6): 608-613.

Warren, J. J., S. E. Bishara, K. L. Steinbock, T. Yonezu and A. J. Nowak. 2001. Effects of oral habits' duration on dental characteristics in the primary dentition. J. Am. Dent. Assoc. 132(12): 1685-1693.

Younes, S. A. E. 1984. Maxillary arch dimensions in Saudi and Egyptian population sample. Am. J. Orthod. 85(1): 83-88. 